\title{
Too Much Feeling: S.E. Hinton's The Outsiders (1967), Conflicting Emotions, Identity, and Socialization
}

\section{Lydia Wistisen $^{1}$}

Published online: 21 April 2020

(c) The Author(s) 2020

\begin{abstract}
This article argues that emotions are utilized for norm breaking, identity formation, and socialization in S.E. Hinton's YA novel The Outsiders (1967). Drawing on the history of emotions studies, it investigates how emotional expressions are utilized to negotiate and contest given emotional norms on the one hand, and Young Adult literary conventions on the other. The point of departure is intersectional and focuses on the relationship between emotion, power, and socialization. In particular, the article considers how intersections of age, gender, and class relate to depictions of feeling and establishing of new emotional norms. The article shows that the feelings that the main character Pony expresses are part of a reiterative process of negotiation of power; they work as instruments for changing emotional norms connected to his age, class, and gender.
\end{abstract}

Keywords S.E. Hinton · The Outsiders · Young Adult literature · Emotions · Masculinity $\cdot$ Post-war youth culture

In S.E. Hinton's pioneering YA novel, The Outsiders (1967), emotions are utilized for norm breaking, identity formation, and socialization. The novel revolves around a deadly conflict between two youth gangs, the greasers and the Socs. The greasers are part of a youth subculture that was popularized in the 1950s and 1960s by predominantly working-class teenagers in the United States - the word "greaser" was applied to members because of their characteristic Elvis-Presley-inspired

\footnotetext{
Lydia Wistisen is a researcher and lecturer at the Department for Culture and Aesthetics at Stockholm University. Her research interests include YA, picture books, emotion history, intersectionality studies, space and place, and urbanity. She is a member of the editorial board of Nordic Journal of ChildLit Aesthetics and the guest editor of the latest volume of Swedish Barnboken: Journal of Children's Literature Research. Additionally, she reviews children's and Young Adult literature for the Swedish daily newspaper Dagens Nyheter.
}

Lydia Wistisen

lydia.wistisen@littvet.su.se

1 Department of Culture and Aesthetics, Stockholm University, Stockholm, Sweden 
greased-back hair (Moore, 2017, p. 138). Soc, on the other hand, is short for Social and refers to rich upper-middle-class teenagers. In one passage, narrator (and greaser) Pony discusses what separates the two types of youth with the Soc, Cherry: "It's not money, it's feeling - you don't feel anything, and we feel too violently" (2006/1967, p. 38). They both agree.

These conflicting emotional styles are characteristic features, not only of Hinton's novel, but of contemporary views of youth at the time. Emotion historians such as Phillip Sterns and Sally Robinson have argued that a fundamental shift in the hegemonic emotional norm occurred in America in the early twentieth century. Although the word "cool" became a widespread term for an emotional style only in the 1960s, it signifies a feeling that was already evident in the preceding decades (Sterns, 1994, p. 231). Whereas the Victorians believed all emotions to be socially useful in one way or another, twentieth-century Americans called for a far more restrained and less intense emotional style, where emotions should be controlled and no emotion should dominate one's thought processes (Sterns, 1994, p. 184; cf. 1999; Robinson, 2002, pp. 210-211). This restraint, however, accompanied an equally widely recognized belief that male sexual energies must be released. The coexistence of an ethic of emotional control with a contrasting discourse encouraging male sexual expression generated confusion amongst men (Robinson, 2002, pp. 210f). This contradiction was in turn further complicated by a simultaneous growth in consumer culture. Since advertising depends on impulse and therefore demands expressiveness, a kind of emotional informality was encouraged in parallel with the demand for self-control (Sterns, 1994, p. 211).

In the midst of the conflicting demands of post-war society and consumer culture sits the contemporary youth culture of Hinton's The Outsiders. During the postwar era a youth culture spread around the Western world, as a growing number of young people were questioning the dominant values of society. This process, with its 1950 s teenage revolt and 1960s counterculture, produced a shift in how the young generation was thought of and represented in everything from literature and film to politics, psychology, and sociology. For the first time in history, teenagers became important cultural assets and trendsetters, consequently generating a plenitude of interpretations and representations (Green, 1999, p. 1). Studies on youth turned into independent areas of research, with developmental psychologists and sociologists such as Erik Erikson, Anna Freud, Edgar Z. Friedenberg, and Paul Goodman developing G. Stanley Hall's previously uncontested work on adolescence (Hall, 1904; Erikson, 1950; Friedenberg, 1959, 1965; Goodman, 1960; Freud, 1965). The era was obsessed with the juvenile delinquency that, due to the social, economic, and familial disruptions caused by World War II, had been and was still increasing. The obsession gave rise to a great deal of more-or-less sensational fiction and nonfiction titles about angry young men (Abate, 2013, pp. 155ff). Furthermore, in novels such as J. D. Salinger's The Catcher in the Rye (1951), Jack Kerouac's On the Road (1957), Joyce Johnson's Come and Join the Dance (1962) and Sylvia Plath's The Bell Jar (1963), the emotional norms of adult middle-class society were being breached by youngsters who were too emotional, or not emotional enough.

Hinton's The Outsiders engages with this tendency from a rather different perspective. The novel was written and published for a young audience, which turns the 
violent and provocative theme, together with the narrative voice and didactic point of view, into something groundbreaking. Hinton is often said to have renewed, or even invented, modern YA literature (Trites, 2000, p. 9; Cart, 1996, p. 43). This article thus investigates how emotional expressions are utilized to negotiate and contest given emotional norms on the one hand, and Young Adult literary conventions on the other. I aim to explore the connection between new YA literary strategies and a changing politics of emotion in post-war North American culture. The point of departure is intersectional and focuses on the relationship between emotion, power, and socialization. In particular, I will consider how intersections of age, gender, and class relate to depictions of feeling and the establishment of new emotional norms.

Although emotions occupy a central position within the novel, previous scholarship has mainly focused on the ways in which it deals with power, socialization, and ideology (Trites, 2000; Tribunella, 2007; Beals 2018), and on its representation of mainstream culture, consumerism, capitalism, and class difference (Abate, 2013; Tribunella, 2007; Beals 2018). Trites and Tribunella identify ways in which Hinton's debut fosters its readers by reproducing the dominant ideology of the middle class and of the American school system. As Tribunella puts it, The Outsiders is "a key prototype of the new realist novel for young adults, but also an explicitly didactic one" (2007, p. 89). He argues that the novel undermines its own purported critique of social class mainly by its endorsement of American education. Rather than radically challenging class society, the novel maintains and reproduces the social order (2007, pp. 95-99). He and Trites both presume that the nature of Young Adult literature is tightly connected to issues of power. Trites states: "During adolescence, adolescents must learn their place in the power structure. They must learn to negotiate the many institutions that shape them: school, government, religion, identity politics, family, and so on" (2000, p. x). This negotiation is often represented by a movement from rebellion and alienation to a desire for approval and an ambition to participate in the social structures that initially gave rise to a sense of opposition and alienation (Reynolds, 2007, p. 72). Conversely, Sandra Beals suggests that the narrative structure of Hinton's novel nonetheless encourages a subversive reading. She states that "the narrative structure of The Outsiders invites readers to question the picture of society that classist ideology naturalizes, freeing them up to imagine and hope for a world without classist violence" (2018, p. 183). I will argue that Hinton's representations of emotions invite a similar questioning of social norms, conventions, and ideology. Feelings play a vital part in the subversive questioning of society, as well as in the didactics of The Outsiders.

\section{Emotions and Juvenile Fiction}

The theoretical and methodological framework of this article is chiefly constituted from research on the history of emotion and, to some extent, affect theory. Only in recent years has the work of literary scholars begun to take theoretical form under the heading of the history of emotions, applying concepts such as William Reddy's "emotives" and "emotional regime/style" or Barbara Rosenwein's "emotional communities" to literary material (Plamper, 2012). 
A growing interest in the intersections of emotions and age is also apparent. Two essay collections - Learning How to Feel: Children's Literature and Emotional Socialization, 1870-1970 (Frevert, 2014) and Affect, Emotion, and Children's Literature: Representation and Socialization in Texts for Children and Young Adults (Bullen et al., 2018) - demonstrate a great variety of ways to work with emotion and juvenile fiction in terms of norms, identity, and power, amongst other perspectives. While the first anthology utilizes a methodology taken solely from the history of emotion, the second also contains several chapters which apply theory of mind to literary material - a similarly growing field (Nikolajeva, 2018; Kokkola, 2018).

In general, novels written for young adults are used "as tools for emotional socialization, enculturation, political persuasion, and moral or ethical education" (Bullen et al., 2018, p. 2). Nevertheless, Eitler et al. point out that the emotional repertoire offered to children and young adults within children's and YA literature has gone through major changes over the decades. Since the late nineteenth century, there has been increasing attention to the pluralization of emotions. In particular, the role of morals has been shifting, forbidding or permitting feelings to be acted out, and the emphasis on the empowerment of children by allowing them to feel angry or happy has grown stronger; in connection with this, juvenile peer groups have been represented as ever more important for emotional growth. Moreover, the responsibility of children for their own feelings and personal self-development increased during the twentieth century. These processes are neither linear nor homogeneous; countertendencies and conflicts can of course be found across time (Eitler et al., 2014, pp. 14-17). In the collections mentioned above, however, there is a strong emphasis on children, children's literature, and, especially in the second, cognitive theory. This article, with its highlighting of emotion history, youth, and YA, will therefore contribute valuable insights into the emotional socialization of teenagers.

There are some essential assumptions underpinning almost all studies of emotion. Feelings are neither strictly biological nor chemical, nor wholly created by language and society; instead, they are something in between, shaped, repressed, and expressed differently in different social, cultural, and historical contexts. Emotions are closely linked to power structures and entwined with the construction of social identities and hierarchies (Plamper, 2012). However, there are different ways of describing the emotional style(s) or norm(s) of a particular period. Some approaches are rather monolithic, presuming one style to be representative of the period (e.g. Reddy, 2008), whereas others emphasize the interactions of dominant and subordinate styles, as well as the plurality and coexistence of deviating styles (e.g. Gammerl, 2012; Rosenwein, 2006). Since The Outsiders depicts a power negotiating process that can be interpreted as both didactic and subversive, I will proceed from the latter approach.

Rosenwein's concept of "emotional communities" refers to "groups in which people adhere to the same norms of expression and value - or devalue - the same or related emotions" (Rosenwein, 2006, p. 2). The term explains how individuals can express and perform emotions differently in different contexts, thus being part of several communities with varying emotional norms and preferences. It is especially important in dealing with YA literature, which is in itself situated at the intersection 
between different age-related communities. In the case of The Outsiders it is productive for considering the different emotional styles of the greasers and Socs.

For the discussion of the subversive potential of Hinton's novel, Sara Ahmed's understanding of emotion, identity, and change is vital. In The Cultural Politics of Emotion (2004), Ahmed argues that the affect that certain groups of people generate and the emotional responses that consequently emerge, create space for voice and action, as well as enabling the formation of shared identities. Drawing on the work of gender theorist Judith Butler, Ahmed argues that emotions accumulate value and produce affect through repetition. Using emotion historian William Reddy's concept of the "emotive" - a term that describes a speech act expressing feelings - she shows how the repetition of emotion-words, such as "I am cool," alter the state of the person expressing them, as well as designating which bodies belong to an imagined community and which bodies are abject to it (2004, pp. 91f).

My analysis will utilize Ahmed's interpretation of Reddy's concept of the "emotive" to highlight the dynamics and relationships between the conflicting emotions represented in Hinton's novel. By critically comparing how different emotives are used to contest emotional and identity related norms, variations in emotional expression and emotional tension created by social affiliation (age, gender, class) will be explored. As my emphasis is on emotion as statement and process, I will use close reading and discursive analysis as my method. Firstly, I will trace who feels what and how. Secondly, as literary texts sometimes avoid labelling an emotion or emotions, I will consider how emotions operate in the text, what they do on a narrative level. The analysis will examine utterances and descriptions of physical, as well as mental emotional expressions.

\section{Conflicting Emotions}

Previous research on The Outsiders has mainly focused on class conflict. For example, Tribunella views the conflict in the novel as "a clash between conflicting models of youth - on the one hand a nineteenth century and Depression-era model of the child as a necessary economic contributor to the household, and on the other hand the new teenager of the mid-twentieth century whose primary job is going to school and spending money on youth culture" $(2007,89)$. I will argue that The Outsiders can also be read as a discussion of the conflicting emotions and masculinity norms of the post-war era. Hinton is constantly drawing on, questioning, and transforming contemporary discourses at the intersections of masculinity, class, and age.

At the beginning of the story, Hinton introduces the narrator, Pony, by linking him successively with a certain set of emotions, primarily alienation, love, and fear. Walking home by himself from the movies, Ponyboy first thinks of himself being "different" from other people, more perceptive and imaginative (2006/1967, p. 2). Then he starts thinking about his adoration of his easygoing and happy middle brother, Soda, as well as his mixed feelings towards his older and rougher brother, Darry (2006/1967, pp. 2-3). Suddenly, a red Corvair pulls up beside him and out come five hostile young men belonging to the Socs. Pony starts to feel scared (2006/1967, p. 4). These three feelings are prominent in the main body of the novel; 
they encourage action and push the narrative onwards. It is the feeling of estrangement that makes Pony go to the movies by himself, it is the longing for love from his older brother Darry that drives him out of the house the night that the Soc Bob gets killed, and it is Johnny's strong feeling of terror that has him stab Bob. Throughout the novel, emotion is used as a narrative engine: "I can understand why Sodapop and Steve get into drag races and fights so much, though - both of them have too much energy, too much feeling, with no way to blow it off," Pony explains (2006/1967, p. 16, emphasis mine).

In The Cultural Politics of Emotion, Ahmed reflects "on the processes whereby 'being emotional' comes to be seen as a characteristic of some bodies and not others." She states that emotions are tied to the securing of social hierarchy, and thus "become attributes of bodies as a way of transforming what is 'lower' or 'higher' into bodily traits" (2004, p. 4). In this regard, the emotionality that shapes the greaser community, as well as the coolness of the Socs, is dependent on relations of power, which endow the members with meaning and value. In other words, emotions secure the social hierarchy of the novel, mainly by attaching emotions to class. It is a surplus of emotion that separates the greaser community from the upper-middle-class youth, as well as driving the story line forward.

During the 1950s, a crisis of masculinity arose in the United States that affected both adults and teenagers, but in different ways. According to Michael Kimmel in Manhood in America: A Cultural History (1996), this crisis was precipitated by two factors. Firstly, re-entry into civil society after the Second World War proved difficult for many men, who found it hard to live up to the image of being a hero. Secondly, modern corporate capitalism transformed the working conditions of American men by turning small entrepreneurs into hired employees. As the idea of the self-made man had been important throughout United States history, its loss gave rise to a harsh critique (1996, pp. 224-225; 240). In popular works such as David Riesman's The Lonely Crowd (1950), C. Wright Mills' White Collar (1953), and Sloan Wilson's The Man in the Grey Flannel Suit (1955), middle-class manhood is associated with numbness and the suppression of fear, sorrow, and tenderness (Kimmel, 1996, pp. 240-241). The preoccupation of Hinton's contemporaries with juvenile delinquency can in turn be understood as a reaction to the crisis in masculinity. The delinquent represents individual autonomy, power, and control. He provides American men with a negative stereotype against which to play out their yearnings (1996, p. 243).

The emotional style of the Socs is related to those conflicting norms. Cherry, for example, describes the difference between the greasers and the Socs in these terms: "You greasers have a different set of values. You're more emotional. We're sophisticated - cool to the point of not feeling anything. Nothing is real with us" (Hinton, 2006/1967, p. 38). The emotive "cool" is brand new and in this context associated with wealth and upper-middle-class youth. It is a normative, and in some ways hegemonic, emotional state of mind, clearly designated for successful men and women (Sterns, 1994, p. 184). However, within Cherry's statement lies a negativity that breaches the facade of self-control and instead displays the disadvantages of managing emotion. To be cool is presented not as a goal but rather as something restricting, that hides one's true self. The emotive is clearly suppressing feelings; for 
example, Pony observes that Socs are "always behind a wall of aloofness, careful not to let their real selves show through" (2006/1967, p. 38). Interestingly, both too much and too little feeling provoke violence, and the two gangs "take turns getting [their] names in the paper" (2006/1967, p. 38).

Neither style is depicted as an ideal. Instead, Hinton is playing with both stereotypes, infusing them with positively coded feelings and pointing out similarities rather than differences between delinquent and normative boys. Pony's oldest brother Darry is especially interesting in the context of conflicting emotional communities. Hinton depicts him as an individual who expresses and performs emotions differently in different contexts (cf. Rosenwein, 2006, p. 2). Darry is part of several communities with varying norms, namely the greasers, the Socs, and grown-up society. Being the oldest brother, Darry gave up school to support his younger siblings. As Trites has pointed out, he therefore functions as a father figure for Pony (Trites, 2000, p. 60). While Darry was still in school, he was popular and part of the Socs community. In the first half of the novel he expresses coolness in a comparable way. However, towards the end, he manifests himself as a greaser when he fights his old friends.

Another example of Hinton's play with emotional stereotypes is to be found at the end of the novel. After Pony's best friend Johnny kills Bob, the two boys run away and hide out in an abandoned church in Windrixville. One day, they find the church on fire with children trapped inside. They manage to rescue the children from the burning church, but Johnny ends up with severe burns. He dies at the hospital and not long after another greaser, Dally, is killed by the police, leaving Pony heartbroken and emotionally confused. In an important passage, Pony flips through the pages of Soda's yearbook and finds a picture of Bob. Gradually, he starts to see the boy behind the wall: "I looked at Bob's picture and I could begin to see the person we had killed. A reckless, hot-tempered boy, cocky and scared stiff at the same time" (2006/1967, p. 162). The description is similar to that of his brother, Soda, and other greaser friends. Hinton thus undermines the boundaries between "lower" or "higher" emotions and disturbs the initial emotional social hierarchy of the novel. In particular, the emotional expression of Pony is breaking with stereotypical American masculinity norms. Pony is not cool, he is the opposite of the hegemonic emotional norm, where a man must always be in control of his emotions. Instead, his emotions are constantly gaining control over his thought processes.

\section{Fear and Love}

Feelings of fear and love dominate Hinton's novel; the sense of dread could very well be the signature feeling of the plot. The emotive "scared" is used more than any other, and moreover for describing numerous sensations. It is usually connected to danger, but also to timidity: "The girl looked at me. I was half-scared of her. I'm half-scared of all nice girls, especially Socs" (p. 22). In Hinton's interpretation the sensation of dread is physical, leading to both action and change of appearance: "I was sweating something fierce, although I was cold. I could feel my palms getting clammy and the perspiration running down my back. I get like that when I'm real 
scared.[...] I knew I was as white as I felt and I was shaking like a leaf" (pp. 4; 8). The emotion is an overwhelming and bodily experience, which breaks with norms of manhood, as well as contravening the literary conventions of pre-war juvenile and pulp fiction.

It is typical of the extended emotional repertoire of post-war juvenile literature that the protagonist and hero of the story is genuinely afraid. According to Bettina Hitzer, readers began to encounter a multitude of narratives relating to fear during the latter half of the twentieth century. Primarily, fear is no longer represented in opposition to courage; instead, the feeling is fashioned as a necessary step towards courage. Heroes, such as Pony, start to acknowledge their emotional vulnerability. The emotion has a heuristic capacity and connects humans rather than separating them from each other (Hitzer, 2014, pp. 181-182). By the end of The Outsiders, the meaning of the emotive changes. The church where Pony and Johnny have been hiding is on fire and they can hear children yelling from inside. When the two boys start to make their way through the flames in search of the trapped children, Pony's feelings change: "I should be scared, but I'm not.[...] Why aren't I scared?" (2006/1967, p. 92). There is no answer to the question, but the reader can understand that it has to do with courage. Likewise, Johnny, earlier described as "a little dark puppy that has been kicked too many times," has changed: "Johnny wasn't behaving at all like his old self.[...] He wasn't scared either. That was the only time I can think of when I saw him without that defeated, suspicious look in his eyes" (2006/1967, p. 92). After the rescue, an adult says that they are "the bravest kids" he has seen "in a long time" (2006/1967, p. 95). In the paper the headline reads "JUVENILE DELINQUENTS TURN HEROES," but as Two-Bit declares: "Y'all were heroes from the beginning. You just didn't 'turn' all of a sudden" (2006/1967, p. 107). The comment shows that scared bodies do not have to be abject to the imagined community of heroes (cf. Ahmed, 2004).

The representation of fear is one of the aspects that separates Hinton's depiction of the greasers from other contemporary portrayals of juvenile delinquents within popular adult literature and film. In her study on the homicide tradition in children's literature, Michelle Ann Abate points to the "portrayal of gang violence [...] fast pace, shocking subject matter, and cinematic quality" of The Outsiders as something new to YA and shows how Hinton incorporates elements from contemporary pulp aesthetics (2013, p. 150). The Outsiders echoes passages from various narratives (fiction and nonfiction) about juvenile delinquency - cheap paperbacks, movies, investigations - and Pony refers to them several times (Abate, 2013, p. 165). However, apart from the lack of dirty language, drugs, and sex (Abate, 2013, p. 169), the anxiety and dread of the main character is what makes Hinton's novel stand out.

Another thing that separates The Outsiders from paperback stories of juvenile delinquents is the representation of love. The feeling plays a vital part in the narrative, particularly in the description of the greaser community. Beljan and Gammerl trace an alteration in children's and Young Adult literature representations of love after the mid-twentieth century, as the democratic ideal of equality demanded a broader acceptance of and higher respect for the needs of others (2014, p. 116). This led to an increase in the importance of peer groups in love motifs: "The notion that relationships among peers were best suited for youngsters to learn how to 
love gained currency during the twentieth century. Earlier books, like those about orphans, had often marked the absence of parents as a problem" (2014, p. 120).

In line with the new tendency, Hinton portrays the greaser community as highly affectionate. As several of the boys are without loving parents - Pony and his brothers recently lost theirs in a car accident and Johnny's are not to be counted on - the peer group has to teach them how to feel: "If it hadn't been for the gang, Johnny would never have known what love and affection are" (2006/1967, p. 12). Many scenes are intimate and Hinton often places the boys in physical proximity: "I put my arm across his shoulders to warm him up.[...] I leaned against him and bawled until I went to sleep" (2006/1967, pp. 73; 75). The emotional community of the greasers provides the boys with the tenderness missing from their relationships with their parents. The community thus creates space for actions of love and vulnerability, as well as enabling the formation of a more sensitive masculine identity (cf. Ahmed, 2004, p. 91).

\section{Watching the Sunset}

In the context of subversive emotions and norm breaking, there is one motif that I would like to discuss further because of its importance for the representation of Pony's vulnerability and sense of estrangement: watching the sunset/sunrise. At the end of the previously mentioned conversation on the differences between the greasers and the Socs, Cherry suggests that Pony is different from other boys:

"I'll bet you watch sunsets, too." She was quiet for a minute after I nodded. "I used to watch them, too, before I got so busy..."

I pictured that, or tried to. Maybe Cherry stood still and watched the sun set while she was supposed to be taking the garbage out. Stood there and watched and forgot everything else [...]. Maybe the two different worlds we lived in weren't so different. We saw the same sunset. (2006/1967, pp. 40-41)

The watching of sunsets is here associated with Pony's sensitivity and sweetness. As Cherry describes him, he is "too sweet to scare anyone.[... N]ot innocent. You've seen too much to be innocent. Just not... dirty" (2006/1967, p. 26). The image of Cherry watching the sunset that Pony is visualizing is part of her past, or of her childhood. Nowadays Cherry is too "busy":

You know, sometimes I'll catch myself talking to a girl-friend, and realize I don't mean half of what I'm saying. [...] "Rat race is a perfect name for it," she said. "We're always going and going and going, and never asking where. [...] It seems like we're always searching for something to satisfy us, and never finding it. Maybe if we could lose our cool we could." (2006/1967, p. 38)

A critique of the concept of the self-made man echoes in Cherry's declaration, which can be interpreted either as a condemnation of corporate capitalism and the endless search for success, or as an illustration of "what social theorists like Charles Taylor have described as the malaise of modernity" (Tribunella, 2007, p. 94). The 
endless progress of the "rat race" is a part of American consumer society, as well as firmly related to the generations who came of age in the 1950s and 1960s and the class mobility that they were expected to participate in. The critique is recognizable from White Collar, in which Mills describes modern men as "cogs in a business machinery that has routinized greed and made aggression an impersonal principle of organization" (Mills, 1951, pp. 108f), but also from another groundbreaking novel on American youth, J.D. Salinger's The Catcher in the Rye (1951). Salinger's narrator, Holden Caulfield, is constantly criticizing the grown-up middle-class community for its adoration of progress, in a manner similar to Cherry's: "Take most people, they're crazy about cars.[...] and if they get a brand-new car already they start thinking about trading it in for one that's even newer" (1951, pp. 169-170). The difference between the two worlds of the greasers and the Socs is related to class, age, and time. Coolness is an inevitable part of growing up as a member of modern capitalist society.

Another description of Pony watching the sunrise reinforces the connection between emotion and time. The setting is outside the abandoned church where Pony and Johnny hide after killing Bob. Early one morning, on the steps at the back of the church, he and Johnny watch the sun rise:

The sky was lighter in the east, and the horizon was a thin golden line. The clouds changed from gray to pink, and the mist was touched with gold. There was a silent moment when everything held its breath, and then the sun rose. (2006/1967, p. 77)

It is noteworthy that the scene is set outside a church. Different spaces are associated with and evoke different emotions and emotional expressions (Pernau, 2014, p. 542). In the past, after the death of Pony's parents, the boys used to go to church together. One day the other boys came along, misbehaved, and so embarrassed Ponyboy and Johnny that they never went to a sermon again. This incident can be interpreted as a representation of the secularization of modern society. In Hinton's novel modernity has led to a lack of space for contemplation; as Cherry puts it: "Things are rough all over" (2006/1967, p. 35; cf. Tribunella, 2007, p. 91). The church has lost its social and cultural significance, and nothing is there to replace it, except maybe movies. Even though the deserted church at first gives Pony "a kind of creepy feeling" (2006/1967, p. 67), it functions as an emotional refuge for the two boys. Reddy's thoughts on the power relations between different emotional styles are somewhat simplistic, but I would like to draw on his idea of emotional refuges. The concept explains those physical or social spaces "that provide safe release from prevailing emotional norms and allow relaxation of emotional effort" (Reddy, 2008, p. 149). The church represents a space where Pony and Johnny can be vulnerable and, for example, cry until they are "all cried out" and can "take whatever was coming" (2006/1967, p. 75).

Moreover, two symbolic events occur at the church. Firstly, both boys cut off the long oily hair that makes them greasers: "Our hair labeled us greasers, too - it was our trademark. The one thing we were proud of. Maybe we couldn't have Corvairs or madras shirts, but we could have hair" (2006/1967, p. 71). The act is emblematic and filled with meaning. If they are caught, the judge will force them 
to get haircuts because it is the only thing that can be taken away from juvenile delinquents without assets. The cutting of the hair seems necessary in turning Johnny and Ponyboy into heroes.

Secondly, after watching the sun rise, Pony recites a poem by Robert Frost:

Nature's first green is gold,

Her hardest hue to hold.

Her early leaf's a flower;

But only so an hour.

Then leaf subsides to leaf.

So Eden sank to grief,

So dawn goes down to day.

Nothing gold can stay. (2006/1967, p. 77)

The boys find it hard to understand the poem, but Johnny observes: "I never noticed colors and clouds and stuff until you kept reminding me about them" (2006/1967, p. 78). Then he starts comparing Pony to his family and once again he is said to be unusual and alienated, this time from two generations: "Soda kinda looks like your mother did, but he acts just exactly like your father. And Darry is the spittin' image of your father, but he ain't wild and laughing all the times like he was. He act like your mother. And you don't act like either one." Pony replies that Johnny is different too: "I couldn't tell Two-Bit or Steve or even Darry about the sunrise and clouds and stuff. I couldn't even remember that poem around them" (2006/1967, p. 78). The boys first agree that they, because of their sensitivity, are different from both their parents and their peers, but then Pony continues, "maybe they are," (2006/1967, p. 78), suggesting that he and Johnny are normal and everyone else different. With this statement Hinton is implying that the emotional style of the two teenagers could very well be a new ideal. In addition, their estrangement is distinct from the two contemporary stereotypical emotional communities described earlier, from the middle class ideal as well as from the juvenile delinquent. Being the youngest characters of the story, the emotional style of Pony and Johnny could be interpreted as pointing towards the future.

\section{Stay Gold}

Some time after Johnny's death, Pony finds a letter from him where he tries, among other things, to interpret the last line of Frost's poem: "Nothing gold can stay." Johnny writes:

I've been thinking about it, and that poem, that guy that wrote it, he meant you're gold when you're a kid, like green. When you're a kid everything's new, dawn. It's just when you get used to everything that it's day. Like the way you dig sunsets, Pony. That's gold. Keep that way, it's a good way to be. (2006/1967, p. 178, emphasis in original) 
The passage has been widely discussed in previous research. For example, Tribunella claims that Johnny's demand that Pony stay gold "signifies remaining innocent and childlike." He continues: "Ironically, then, this foundational novel of young adulthood effectively urges its adolescent readers to turn back, or, since they cannot turn back, at least to practice innocence" (2010, p. 53).

I would like to present a somewhat different interpretation by discussing the subversive aspects of Johnny's wish and its connection to the development of new emotional styles within 1960s masculine and youth communities. The earlier representations of emotives such as "cool" and "scared" imply that both class mobility and aging can be connected to emotional struggles and a dangerous inhibition of feelings. In that regard, to "Stay gold" can also be read as a refusal of the "rat race" and the coolness of the contemporary middle-class norm. One aspect of the text in particular points in that direction. At the beginning of the novel, long before reading the Robert Frost poem, Pony uses the word "golden" to describe his mother: "My mother was golden and beautiful..." (2006/1967, p. 48). The term thus denotes not only innocence and youth, but also the ability to feel, dream, hope; in other words, to watch sunrises.

In that regard, there is a connection between Johnny's wish and the post-war counter- and hippie cultures. The notion of childhood is central to the hippie attitude as it relishes a state of wonder and simplicity; a state of mind that since the Romantic movement has also been framed as childlike (Buckingham, 2018, p. 3). The rules of coming-of-age in pre-1950s society collapsed with the emergence of the consumer society, and the counter-culture of the 1950s and 1960s can thus be seen as part of a broader "rejuvenation" of society in the United States, which enabled the hippie generation to follow through on Peter Pan's resolution never to grow up (Diski, 2010, p. 3; Green, 1999, p. 1).

In earlier times, the relationship between youth and adult was founded on an idea of adjustment. In 1904, to give a foundational example, influential developmental psychologist G. Stanley Hall stated that society is founded on a generational conflict, where the younger generation must adjust to the older one. However, after the Second World War, new views on teenagers were being launched. For instance, in the essay "The Problems of Generations" (1961), Bruno Bettelheim argued that the emotional need of adults to see their way of life continued by the coming generations disappeared with the advent of modern mass society: "Short of such a desire, the older generation has little psychological need for youth.[...] While youth may still have some emotional and economic need for parents, most parents have little emotional need, and very few an economic one, for a youth striving to be free of its elders" (p. 68). Influential developmental psychologist Erik Erikson presented a contradictory perspective:

It is the young who, by their responses and actions, tell the old whether life as represented by the old and as presented to the young has meaning; and it is the young who carry in them the power to confirm those who confirm them and, joining the issues, to renew and to regenerate, or to reform and to rebel. (1965, p. 24.) 
Either way, the relationship between the younger and older generation has clearly changed. It is noteworthy that the phrase "generation gap" was coined in 1967 (Green, 1999, p. x).

In The Outsiders, the closest thing to a generation gap lies in the relationship between Pony and his older brother Darry. The feeling of not being loved by Darry is at the core of the narrative: "Darry love me? I thought of those hard, pale eyes.[...] Darry doesn't love anyone or anything, except maybe Soda. I didn't hardly think of him as being human" (2006/1967, p. 18). The negative descriptions continue: "He's hard as a rock and about as human. He's got eyes exactly like frozen ice. He thinks I'm a pain in the neck" (2006/1967, p. 42). Not until the end of the novel does Pony understand that his brother does indeed love him. Trites interprets the ending: "Pony cannot grow to maturity until he can understand his brother's strictness as an act of love; in other words, he cannot mature until he accepts and forgives his symbolic father figure" (2000, p. 60).

From the perspective of emotions, however, this statement is only partly true. Trites overlooks the fact that Darry also changes throughout the narrative. After the fire, he undergoes a transformation, which precedes Pony's understanding and acceptance. For one thing, his eyes are not described as cold any more: "his eyes were pleading" (2006/1967, p. 97).He is also unexpectedly emotional:

Suddenly I realized, horrified, that Darry was crying. [...] In that second what Soda and Dally and Two-Bit had been trying to tell me came through. Darry did care about me, maybe as much as he cared about Soda, and because he cared he was trying too hard to make something of me. [...] I wondered how I could ever have thought him hard and unfeeling. (2006/1967, pp. 98-99)

Only after Darry has "lost his cool," does Pony manage to forgive him and see him for what he is, a young man: "I suddenly realized that Darry was only twenty, that he wasn't so much older that he couldn't feel scared or hurt and as lost as the rest of us. I saw that I had expected Darry to do all the understanding without even trying to understand him" (2006/1967, p. 176). Something similar happens to Pony's perception of the Soc Randy at the end of the novel: "I took a good look at him. He was seventeen or so, but he was already old.[...] Cherry had said that her friends were too cool to feel anything, and yet she could remember watching sunsets. Randy was supposed to be too cool to feel anything, and yet there was pain in his eyes" (2006/1967, pp. 115-116).

With characters such as Randy and Darry, Hinton is trying to bridge the gap between generations by showing the reader how to understand the older generation and their expression of love - an attentive reader will probably understand what Soda, Dally, and Two-Bit are talking about long before Pony does. However, the emotional style of Pony is the ideal of the novel and Darry therefore has to rediscover his vulnerability, in other words, return to gold. 


\section{Emotional Socialization}

The changing politics of emotion that Hinton thematizes is connected to the development of a modern Young Adult literature. The emotionality of the greaser community, as well as the exhortation to watch sunsets and stay gold, are part of a literary strategy. In an interview in the New York Times Book Review, Hinton criticized contemporary literature for teenagers for being detached from reality: "Teenagers today want to read about teenagers today. The world is changing, yet the authors of books for teenagers are still 15 years behind the times.[...] Nowhere is the drive-in social jungle mentioned. In short, where is the reality?" (Hinton, 1967, p. 26).

In line with this comment, the implied reader of The Outsiders is constructed as Pony's peer. Pony often addresses the reader directly, and expressions such as "if you know what I mean" help establish a close relationship between narrator and reader (Beals, 2018, p. 189). The intimacy that this type of narration creates is typical of twentieth-century YA: two earlier and canonized examples are Maureen Daly's Seventeenth Summer (1942) and Salinger's The Catcher in the Rye. In addition, the narrative technique is tied to the concept of a generation gap and the growing importance of juvenile peer groups. Eitler et al. demonstrate how the influence of parents and other grown-ups decreases in children's and Young Adult literature after World War II, as a way of "empowering children" (2014, p. 16). Hinton is empowering the reader emotionally, and the intimate tone of the narration is used as a tool for emotional socialization. Pony's story instructs the reader in how to navigate a society of conflicting emotional styles. It teaches what modes of emotional expression are expected, and defined as valuable or harmful in different contexts. The reader is thus emotionally socialized by Pony's story (cf. Day, 2013).

Finally, I want to return to Trites' reading of The Outsiders and to the definition of YA as a representation of a negotiation of power where the adolescent always learns her or his place in the power structure (Trites, 2000, p. x). In line with this, Tribunella sees The Outsiders as "an explicitly didactic" novel and argues that Hinton "employs didacticism to gain legitimacy for YA literature as a new undertaking" (2007, p. 89; 2010, p. 35). To some extent, Pony learns his place in society and returns from his adventures a hero and model schoolboy. Hinton is for example institutionalizing the feelings of Pony when the whole story, at the end of the novel, turns out to be a school assignment (cf. Tribunella, 2007, p. 97).

At the same time, however, Pony's feelings transform contemporary Young Adult fiction, making room for a plurality of emotions, scared heroes, and sensitive juvenile delinquents. From the late 1960s onwards, the intimate emotionality of The Outsiders became a standard feature of the Young Adult novel, and today it is prevalent (Day, 2013, p. 4). It is also important to bear in mind that The Outsiders is a consumer good, and very successful as such. The expressive emotional style of the greaser community is related to the 1950s and 60s language of advertising, which likewise stands in contrast with the restrained emotional style of the 
American middle-class. Emotion sells and new popular youth culture is therefore promoted with strong feelings. One great example is the movie Rebel Without a Cause (1955), a groundbreaking attempt to depict the generational conflict of the 1950s with James Dean in the leading role. The emphasis on emotion is strong - Dean is alternately angry, sad, and tender - and it is significant that the slogan of the movie trailer was: "Powerful so powerful... Sensitive so sensitive... Entertainment of unforgettable emotional impact!".

In conclusion, Hinton's representation of emotions does encourage a subversive reading, as Pony refuses to participate in the emotional structures that gave rise to his initial sense of alienation. Emotional expressions and speech acts are performative; they are instruments for directly creating, contesting, and changing communities (cf. Ahmed, p. 91). In The Outsiders, different emotives are used to challenge emotional and identity related norms, as well as aesthetic conventions. The novel is situated at the intersection of different age, class, and time related emotional communities: the adult world, with its demand for restraint and didactics, and the teenage culture of Pony and of Hinton - who was only fifteen when she started writing the novel. Moreover, the refusal of progress and soft masculinity of the counterculture, as well as the philosophy of the hippies and their encouragement of a child-like state of mind, support the emotional style of Pony. The feelings that Pony expresses are part of a reiterative process of negotiation of power; they work as instruments for changing emotional norms connected to his age, class, and gender. Even though Pony learns his place in society, his emotional style is norm breaking. He will try to stay gold.

Acknowledgements Open access funding provided by Stockholm University.

Open Access This article is licensed under a Creative Commons Attribution 4.0 International License, which permits use, sharing, adaptation, distribution and reproduction in any medium or format, as long as you give appropriate credit to the original author(s) and the source, provide a link to the Creative Commons licence, and indicate if changes were made. The images or other third party material in this article are included in the article's Creative Commons licence, unless indicated otherwise in a credit line to the material. If material is not included in the article's Creative Commons licence and your intended use is not permitted by statutory regulation or exceeds the permitted use, you will need to obtain permission directly from the copyright holder. To view a copy of this licence, visit http://creativecommons.org/licen ses/by/4.0/.

\section{References}

Abate, Michelle Ann. (2013). Bloody Murder. Baltimore: Johns Hopkins University Press.

Ahmed, Sarah. (2004). The Cultural Politics of Emotion. New York: Routledge.

Beals, Sandra. (2018). Modeling Liberation: Audience, Ideology, and Critical Consciousness in S.E. Hinton's The Outsiders. Children's Literature Association Quarterly, 43(2), 183-201.

Beljan, Magdalena and Benno Gammerl. (2014). Wendy's Love. In Ute Frevert (Ed.), Learning How to Feel: Children's Literature and Emotional Socialization, 1870-1970 (pp. 115-134). Oxford: Oxford University Press.

Bettelheim, Bruno. (1961). The problems of Generations. In Erik H. Erikson (Ed.), Youth: Change and Challenge (pp. 64-75) New York: Basic Books. 
Buckingham, David. (2018). Children of the Revolution? The Counter-Culture, The Idea of Childhood, and the Case of Schoolkids Oz. In Strena Recherches sur les livres et objets culturels de l'enfance. 13, 1-16.

Bullen, Elizabeth, Moruzi, Kristine, and Smith, Michelle J. (2018). Children's Literature and the Affective Turn: Affect, Emotion, Empathy. In Kristine Moruzi et al. (Eds), Affect, Emotion, and Children's Literature: Representation and Socialization in Texts for Children and Young Adults (pp. 2-12). New York: Routledge.

Cart, Michel. (1996). From Romance to Realism: 50 Years of Growth and Change in Young Adult Literature. New York: HarperCollins Publishers.

Day, Sara. (2013). Reading Like a Girl: Narrative Intimacy in Contemporary American Young Adult Literature. Jackson: University Press of Mississippi.

Diski, Jenny. (2010). The Sixties. London: Profile Books.

Eitler, Pacal, Olsen, Stephanie, and Jensen, Uffa. (2014). Introduction. In Ute Frevert (Ed.), Learning How to Feel: Children's Literature and Emotional Socialization, 1870-1970 (pp. 2-18). Oxford: Oxford University Press.

Erikson, Erik. (1950). Childhood and Society. New York: Norton.

Freud, Anna. (1965). Normality and Pathology in Childhood: Assessments of Development. New York: International Universities Press.

Frevert, Ute. (Ed). (2014). Learning How to Feel: Children's Literature and Emotional Socialization, 1870-1970. Oxford: Oxford University Press.

Friedenberg, Edgar Z. (1959). The Vanishing Adolescent. Beacon Hill: Beacon Press.

Friedenberg, Edgar Z. (1965). Coming of Age in America: Growth and Adolescence. New York: Random House.

Gammerl, Benno. (2012). Emotional Styles - Concept and Challenges. Rethinking History, 16(2), $1-16$.

Goodman, Paul. (1960). Growing Up Absurd: Problems of Youth in the Organized Society, New York: Random House.

Green, Jonathon. (1999). All Dressed Up: The Sixties and the Counterculture. London: Pimlico.

Hall, Stanley. (1904). Adolescence: Its Psychology, and Its Relations to Physiology, Anthropology, Sociology, Sex, Crime, Religion, and Education I and II. New York: D. Appleton and Company.

Hinton, S.E. (2006/1967). The Outsiders. New York: Speak.

Hinton, S.E. (1967). “Teen-Agers are for Real”. New York Times Book Review (pp. 26-28). 27 Aug.

Hitzer, Bettina. (2014), Jim Button's Fear. In Ute Frevert (Ed.), Learning How to Feel: Children's Literature and Emotional Socialization, 1870-1970 (pp. 173-191). Oxford: Oxford University Press.

Kimmel, Michael. (1996). Manhood in America: A Cultural History. London: Free Press.

Kokkola, Lydia. (2018). Simplified Minds: Empathy and Mind-Modeling in Christopher Paolini's Inheritance Cycle. In Elisabeth Bullen et al. (Eds), Affect, Emotion, and Children's Literature: Representation and Socialization in Texts for Children and Young Adults (pp. 97-114). New York: Routledge.

Mills, C. Wright. (1951). White Collar: The American Middle Classes. New York: Oxford University Press.

Moore, Jenifer Grayer. (2017). Street Style in America: An Exploration. California: Greenwood.

Nikolajeva, Maria. (2018). Emotions and Ethics: Implications for Children's Literature. In Elizabeth Bullen et al. (Eds), Affect, Emotion, and Children's Literature: Representation and Socialization in Texts for Children and Young Adults (pp. 82-97). New York: Routledge.

Pernau, Margrit. (2014). Space and Emotion: Building to Feel. History Compass, 12(7), 541-549.

Plamper, Jan. (2012). The History of Emotions: An Introduction. Keith Tribe (Trans.). Oxford: Oxford University Press.

Reddy, William. (2008). The Navigation of Feeling: A Framework for the History of Emotions. Cambridge: Cambridge University Press.

Reynolds, Kimberley. (2007). Radical Children's Literature: Future Visions and Aesthetic Transformations in Juvenile Fiction. Basingstoke, Palgrave McMillan.

Robinson, Sally. (2002). Men's Liberation, Men's Wounds: Emotion, Sexuality, and the Reconstruction of Masculinity in the 1970s. In Milette Shamir and Jennifer Travis (Eds.). Boys Don't Cry?: Rethinking Narratives of Masculinity and Emotion in the U.S. (pp. 205-230). New York: Columbia University Press. 
Rosenwein, Barbara. (2006). Emotional Communities in the Early Middle Ages. Ithaca: Cornell University Press.

Salinger, J.D. (1951). The Catcher in the Rye. London: Hamilton.

Sterns, Peter N. (1994). American Cool: Constructing a Twentieth-Century Emotional Style. New York: New York University Press.

Sterns, Peter N. (1999). Battleground of Desire: The Struggle for Self-Control in Modern America. New York: New York University Press.

Tribunella, Erik L. (2007). Institutionalizing The Outsiders: YA Literature, Social Class, and the American Faith in Education. In Children's Literature in Education 38(2), 87-101.

Tribunella, Erik L. (2010). Melancholia and Maturation: The Use of Trauma in American Children's Literature. Knoxville: University of Tennessee Press.

Trites, Roberta Seelinger. (2000). Disturbing the Universe: Power and Repression in Adolescent Literature. Iowa City: University of Iowa Press.

Publisher's Note Springer Nature remains neutral with regard to jurisdictional claims in published maps and institutional affiliations. 